\title{
Ghosts in the machines
}

\author{
Ashish S. Shah, MD \\ From the Department of Cardiac Surgery, Vanderbilt University Medical Center, Nashville, Tenn. \\ Disclosures: Author has nothing to disclose with regard to commercial support. \\ Received for publication March 6, 2018; accepted for publication March 9, 2018; available ahead of print April 4, \\ 2018. \\ Address for reprints: Ashish S. Shah, MD, Department of Cardiac Surgery, Vanderbilt University Medical Center, \\ Vanderbilt Medical Center East, 1215 21st Ave S, Suite 5025, Nashville, TN 37232 (E-mail: ashish.s.shah@ \\ vanderbilt.edu). \\ J Thorac Cardiovasc Surg 2018;156:156 \\ $0022-5223 / \$ 36.00$ \\ Copyright (c) 2018 by The American Association for Thoracic Surgery \\ https://doi.org/10.1016/j.jtcvs.2018.03.040
}

Mechanical support in the setting of cardiogenic shock remains an attractive, albeit imperfect, strategy. In this issue of the Journal, Ando and colleagues ${ }^{1}$ report their group's experience with more than 250 patients supported with machines in a variety of configurations in the course of 10 years. The report focuses on basic outcomes and the different configurations that the group uses. During the decade, the team has evolved, and they report improving outcomes with a sternal sparing approach. Embedded in all these machines, however, is the evolution in their thinking about shock. During this period, the group adopted a "shock team" approach and actively looked for ways to minimize the morbidity associated with their devices. The outcomes improved with time, and the group clearly got better at dealing with this issue, although Ando and colleagues ${ }^{1}$ do not explicitly state this.

Although this case series is a testament to improving technologies, it is even more an endorsement of smart people learning from mistakes. In the second era, there were fewer postcardiotomy patients, the initial lactate level was lower, and more extracorporeal membrane oxygenator support was used as a bridge to bridge. All this suggests that the team developed biases that informed their decision making: wisdom comes from bad judgment. One would love to have a more explicit discussion about this-not about the surgical approach, but rather about the systems in place to restore circulation rapidly or the exclusion criteria that they maintained despite rapid program growth. Was there more

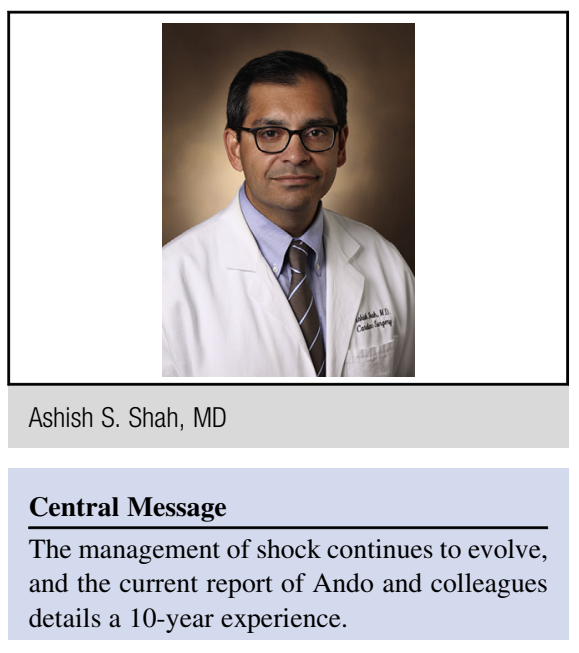

See Article page 157

accountability during the 10 years? How many more people were involved during the decade? Did the program changes lead to cost savings?

The other nagging feeling, when reading this report, is that after 10 years we do not have much more to go on with respect to patient selection: no new biomarkers, no new risk scores. Moreover, the outcomes remain disappointingly poor, with nearly half the patients dead and no mention of the disability among survivors.

Let us hope that future studies examine shock in a serious way. What are the biologic determinants of outcome, how do we reestablish adequate oxygen delivery, and how do we minimize end-organ injury? These machines that mindlessly pump oxygenated blood operate in contrast to the mindfulness and deep thinking of the humans that deploy the devices. Who will be the ghosts in these machines?

\section{Reference}

1. Ando M, Garan AR, Takayama H, Topkara VK, Han J, Kurlansky P, et al. A continuous-flow external ventricular assist device for cardiogenic shock: evolution over 10 years. J Thorac Cardiovasc Surg. 2018;156:157-65.e1. 